\title{
SINERGISTIC USE OF RADAR AND OPTICAL DATA FOR AGRI CUL TURAL DATA PRODUCTS ASSIMILATION: A CASE STUDY IN CENTRAL ITALY
}

\author{
Anniballe R. ${ }^{1 b}$, Casa R. ${ }^{2}$, Castal di F. ${ }^{2}$, Fascetti F. ${ }^{1 b}$, Fusilli F. ${ }^{1 a}$, Huang W. ${ }^{3}$, Laneve G. ${ }^{1 a}$, Marzial etti P. ${ }^{1 a}$, \\ Pal ombo A. ${ }^{4}$, Pascucci S. ${ }^{4}$, Pierdicca N. ${ }^{1 b}$, Pignatti $S^{4}$, Qiaoyun $X^{3-6}$, Santini F. ${ }^{4}$, Silvestro P.C. ${ }^{2}$, \\ Yang $\mathrm{H}^{5}$, Yang $\mathrm{G}^{5}$ \\ ${ }^{1}$ Università di Roma “La Sapienza”, Italy, DIAEE ${ }^{\text {1a }}$, DIET ${ }^{16}$; \\ ${ }^{2}$ Università degli Studi della Tuscia, Italy, DAFNE; \\ ${ }^{3}$ Institute of Remote Sensing and Digital Earth, CAS, Beijing 100094, China; \\ ${ }^{4}$ CNR IMAA, C. da S. Loja, 85050 Tito, Italy, pignatti@imaa.cnr.it; \\ ${ }^{5}$ Beijing Research Center for Information Technol ogy in Agriculture, BAAFS, Beijing, China \\ ${ }^{6}$ University of Chinese Academy of Sciences, Beijing 100049, China
}

\begin{abstract}
The paper describes the preliminary results of the JanuaryAugust 2015 multi-frequency EO data acquisition campaign conducted over the Maccarese (Central Italy) farm. From January to May radar Cosmo SkyMed Ping-Pong (HH-VV), RapidEye and ZY-3 multispectral VHR optical images, as well as in situ data, have been acquired to retrieve biophysical and/or bio-chemical characteristics of soil and crops. LAI trend has been analyzed and compared by using both polarimetric and optical retrieval al gorithms while soil moisture measurements have been compared with the radar backscattering.
\end{abstract}

Index Terms: CSK, Ping-Pong, polarimetric, optical data, multi-temporal, soil moisture, LAI.

\section{INTRODUCTION}

Over recent years the availability of data for EO multisource/platform has greatly increased, thus enabling the improvement of techniques for retrieving environmental variables in the fields of ecosystem functions, natural resource management, natural hazards and Earth system modeling. These variables, however, are rarely used in crop models to derive proxy variables (e.g. yield, consumption of nitrates, proteins content, etc.) of high operational value (quantitative remote sensing). To date the methods based on the use of remote sensing data for monitoring crops and, in particular, of cereal crops both at the local and regional levels, are still far from being effective and operational. This is because they are not yet able to monitor the different stages of agricultural activities, i.e. to detect the crops temporal dynamics in a systematic way to be functional for defining corrective actions at the field scale during the growing crop season.
The present paper deals with a Italian-Chinese initiative aiming at exploiting the combined use of optical and radar satellite data to retrieve bio-physical and/or biochemical characteristics of soil and crops. The synergistic use of high resolution radar and multispectral optical data (considering the lack of satellite hyperspectral imagery until 2017) will be exploited for extracting both soil and crop plant information (e.g., humidity, LAI and biomass) useful to train/assimilate these data into crop growing models such as DSSAT. Crop models can produce val uable information for site-specific agricultural management practices.

\section{DATASET AND SPACE SEGMENT INVOLVED}

The 2015 satellite acquisition plan over the test site of Maccarese (farm located close to Rome - Central Italy) will cover both optical and radar satel lites data acqui sitions.

Concerning the planned radar acquisitions, (i) more than two images per month of Cosmo Sky Med (CSK) Xband radar images (Stripmap Himage with a ground sampling distance - GSD of $3 \times 3 \mathrm{~m}$ and Ping-Pong with a GSD of $15 \mathrm{~m}$ and $\mathrm{HH}-\mathrm{VV}$ polarization) have been reserved; (ii) ALOS (L-band) images will be also acquired by JAXA in the late spring; (iii) Sentinel-1 data (C band) will be considered if acquired close to the CSK acquisitions.

As regards optical resources, Landsat-8 images were used, while HR (SPOT and Rapid Eye) data was requested, through an ESA CAT-1 project, to cover the lack of optical data in the expectation of forthcoming Sentinel-2 data. An acquisition sequence was al so requested for Zi-Yuan 3 (ZY3 ) optical satellite sensors (GSD of about $2 \mathrm{~m}$ ) by the CAS RADI (China).

At present, eighteen CSK Ping-Pong ( $\mathrm{HH}, \mathrm{VV})$, three Landsat-8, one Chris/Proba, three Rapid-Eye and one ZY-3 images were successfully acquired over the Maccarese test site. 


\section{IN SITU EXPERIMENTAL SET UP}

During the 2015 crop season (wheat and maize), field campaigns have been carried out from January to July, as much as possible close to the satellite acquisitions, to collect measurements on: (i) crop (i.e. the LAI, using a LAI-2200, and the chlorophyll leaf content, using a Dualex Force-A; (ii) soil (i.e. the soil water content using a TDR and soil nitrogen content and soil texture from laboratory analyses and also soil roughness by a laser profiler); and (iii) leaf and plant spectral measurements using an ASD FieldSpec Pro FR portable spectroradiometer by utilizing the leaf-clip accessory.

\section{EO DATA PROCESSING OVERVIEW}

Satellite data have been processed by the teams involved in the research according to their expertise and on the data ownership of the mission: the Chinese colleagues are in charge for the ZY-3 optical and GF radar data acquisition and processing, while the Italian team processes the CSK radar data. The RADARSAT and multispectral optical RapidEye images (joint ESA CAT-1 project \#29328) are, instead, processed by both teams. In the first processing step, data have been evaluated and analyzed singularly, while the second further step will include an eventual synergistic use of the data and the retrieved variables.

\subsection{Radar data}

For crop classification based on SAR imagery, classification methods based on neural networks have been tested previously [1] with good results using multitemporal acquisitions of Envisat-ASAR and ERS-2 images and different polarizations, where it was possible to differentiate several crop fields as rape, sugar beets, maize and cereals. Even better performances can be achieved when radar and optical data are merged using suitable techniques [2]. At the same time polarimetric SAR (PoISAR) techniques offer a reliable tool for extracting biophysical parameters, which have been successfully applied in crop monitoring. Polarimetric classifications based on polarimetric decompositions (e.g., Cloud-Pottier H-A-alpha decomposition) put into relevance each scattering mechanism. For this purpose, fully polarimetric data are desired (e.g., Alos-PALSAR imagery), otherwise, a combination of $\mathrm{HH}$ and $\mathrm{VV}$ can be exploited to achieve accurate classifications and $\mathrm{HV}$ if only single polarization data will be available [3] .

In order to estimate the LAI during the growing season, ground LAI data are being collected in the field using the LAI2200c Plant Canopy Analyzer periodically, as near as possible to satellite overpasses. By analyzing the 2014 measurement campaigns outcomes, high correlation (in the order of $77 \%$ ) was observed between LAI values of corn fields estimated by satellite optical images and LAI2200 field LAI collected data. New empirical relationships will be developed in order to correlate LAI field measurements, LAI values from optical imagery as well as indices from radar images. In previous studies, SAR data showed great potential for monitoring LAI (e.g. for rice fields [4] and corn, sorghum and wheat [5]). In particular, radar backscatter was analyzed as a function of LAI showing a good correlation, for instance, when using quadpol Radarsat-2 images.

Finally, several studies [6] and [7] have investigated the correlation between radar backscatter and biomass, finding that different saturation values depends both on SAR frequency band and crop type. During this work, an analysis of the potential of the different SAR frequency bands for biomass retrieval will be carried out for the crops of the study area.

Summarizing, the main objectives of the multi-temporal radar data investigations fall into the following application fields: (i) classify different crop species, (ii) monitor the seasonal cycle of growth of any single crop and (iii) identify anomal ous crop behaviors at the field scale.

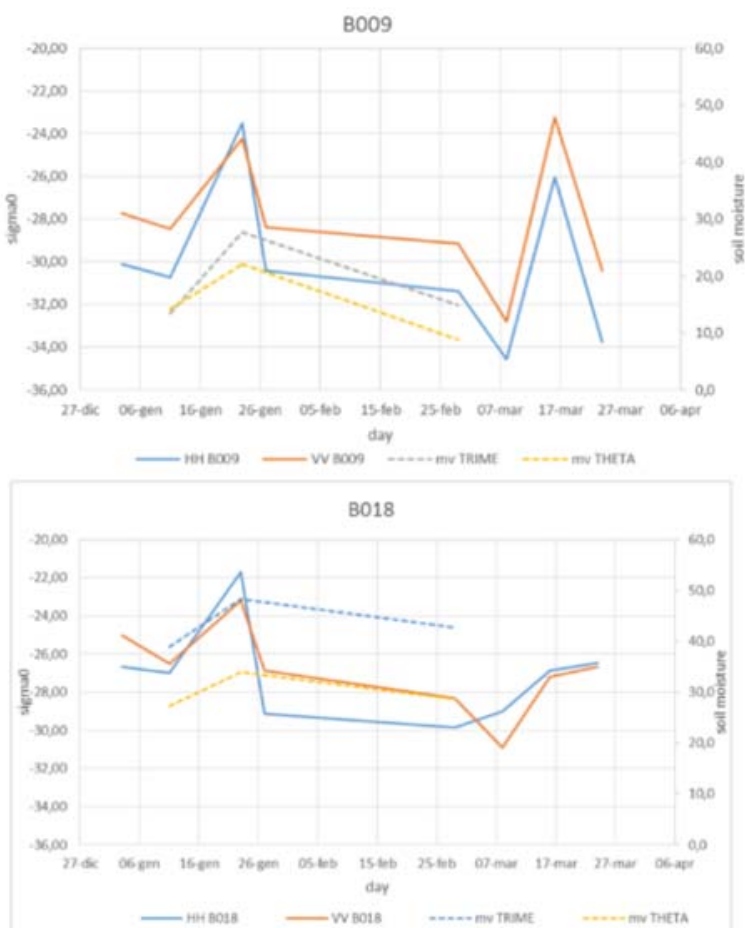

Figure 1: Comparison between CSK backscattered signal and in-situ soil moisture measurements over two wheat fields.

Moreover, since the soil electrical permittivity is influenced by the soil water content, radar data can be also useful to monitor the soil humidity. For such purpose, in situ measurements of soil moisture have been acquired close in time to the satellite acquisitions over the selected fields and, then, compared to the CSK backscattered signals. It is worth to mention that the period of analysis will cover the complete crop-growing phase, starting from the 
plowing/seeding phase. Figure 1 reports the preliminary results, showing the temporal evolution of the CSK backscattered signals ( $\mathrm{HH}$ and VV polarizations) compared to the soil moisture measured over two of the analyzed fields that were still bare in that period. The low values of the CSK backscattered signal are related to the high local incidence angle (around 55 degrees) of the observed area. It is possible to note the high correlation of radar backscatter and soil moisture, in particular, looking at the January $23^{\text {th }}$ acquisition when a strong increase of backscatter can be observed. Such behavior is related to the increase of soil moisture due to strong rain events occurred in previous days. Heavy rain was also recorded just before the acquisition of March $16^{\text {th }}$.

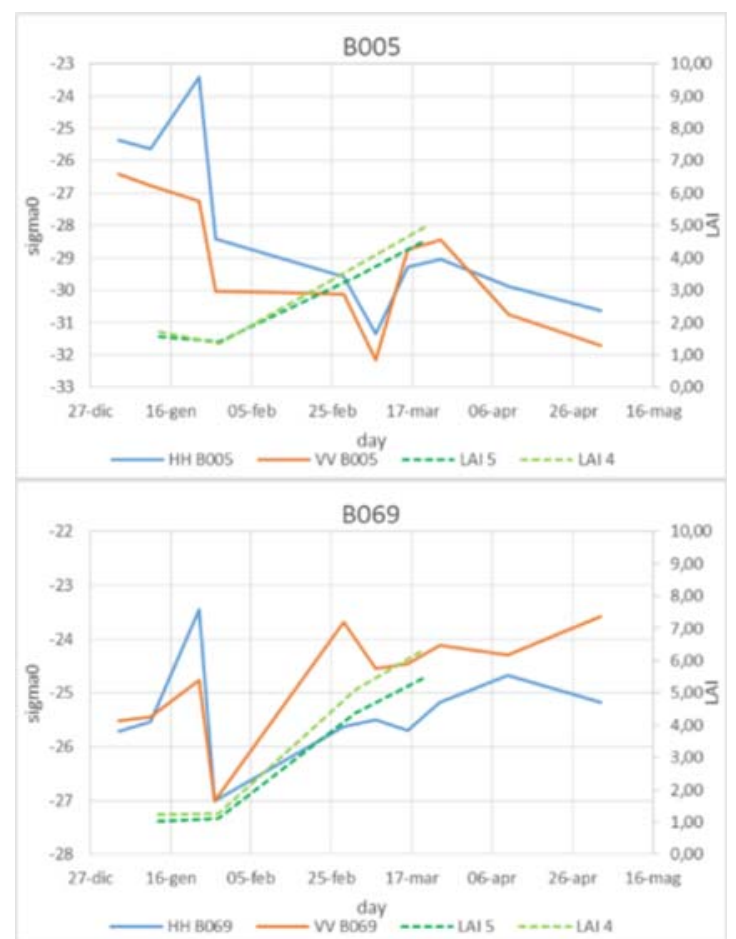

Figure 2: Comparison between CSK backscattered signal and in-situ LAI measurements over a wheat (B005) and faba bean (B069) field selected for the campaign.

Figure 2 presents the correlation of the CSK radar backscatter with the LAI measurements for two fields where wheat (field B005) and bean (field B069) were at an early growing stage. We can still observe a signal related to the soil moisture increase on January $23^{\text {th }}$ and, to some extent, on March $16^{\text {th }}$ in the wheat field. LAI starts to increase around February $5^{\text {th }}$, which seems to produce a different effect in the two fields. In particular, a slight decreasing trend of backscatter has been observed in the wheat field, whereas a significant increasing trend has been observed for the bean field. The latter can be associated to the increase of scattering due to the plant growing, an effect which cannot be appreciated in case of wheat that is known to produce less scattering enhancement of the radar signal.

\subsection{Optical data}

The processing of optical data has been devoted to the retrieval of biochemical and biophysical variables, both at the canopy and leaf levels. This has been mainly achieved through an algorithm based on the training of artificial neural networks (ANN) using PROSAIL model simulations [8] and a regression analysis between spectral indexes and LAI and Chlorophyll [9]. In addition, a special attention has been devoted to the estimation of the variables that will be compared with simulated data of heal thy vegetation, so as to derive absolute indicators for crop stress.

As a preliminary phase of the work, awaiting for the availability of the 2015 full set of multi-spectral data on Maccarese, a preliminary analysis has been carried out using al ready acquired data (both by remote and proximal) at the National Experiment Station for Precision Agriculture $\left(40^{\circ} 10^{\prime} \mathrm{N}, 116^{\circ} 27^{\prime} \mathrm{E}\right)$, Beijing, China in 2002 and in 2014 to retrieve LAI. Regression analysis has been performed among normalized difference vegetation index (NDVI), the modified simple ratio index (MSR) and the modified soil adjusted vegetation index (MSAVI) using hyperspectral airborne data and ground reflectance and LAI data acquired on winter wheat. Estimation results were evaluated using ground truth measured LAl following the k-fold crossvalidation procedure to evaluate the performance of the estimation models.

\begin{tabular}{|c|c|c|c|}
\hline & 2002 & 2014 \\
\hline & & $\mathrm{R}^{2}$ & $\mathrm{R}^{2}$ \\
\hline \multirow{3}{*}{$\begin{array}{l}670 \mathrm{~nm}, \\
800 \mathrm{~nm}\end{array}$} & NDVI & 0.7507 & 0.4807 \\
\hline & MSR & 0.7264 & 0.5585 \\
\hline & MSAVI & 0.7306 & 0.7916 \\
\hline \multirow{3}{*}{$\begin{array}{l}705 \mathrm{~nm}, \\
750 \mathrm{~nm}\end{array}$} & NDVI & 0.7203 & 0.6745 \\
\hline & MSR & 0.7188 & 0.6568 \\
\hline & MSAVI & 0.7043 & 0.8403 \\
\hline \multirow{3}{*}{$\begin{array}{l}\text { Best } \\
\text { correlated } \\
\text { bands }\end{array}$} & NDVI & 0.7960 & 0.8282 \\
\hline & MSR & 0.7817 & 0.8244 \\
\hline & MSAVI & 0.7963 & 0.8673 \\
\hline
\end{tabular}

Table 1 Regression analysis results for the LAl estimation by using the 2002 and 2014 Chinese data set

As preliminary analysis of the optical data acquired on Maccarese during the 2015 winter wheat season (JanuaryMay), two processing paths have been used. The first corresponds to a standard regression analysis between spectral indexes and LAI measured, while the second is based on the application of ANN to obtain maps of biophysical crop canopy variables directly from images. This last approach relies on three main steps: a) creation of a learning database from PROSAIL, b) training the neural networks and finally c) applying the created networks for estimating the requested biophysical variables. 
Table 2 shows the correlation coefficient between Rapid-Eye derived spectral indexes versus LAI and Chlorophyll measured in situ.

\begin{tabular}{|l|c|c|c|c|c|c|}
\hline & LAI & OHL & NDVI & GreenNDVI RE ratio & ChINDI \\
\hline LAl & 1 & & & & & \\
\hline CHL & 0,18 & 1,00 & & & & \\
\hline NDVI & 0,75 & 0,30 & 1,00 & & & \\
\hline GreenNDI & 0,71 & 0,23 & 0,94 & 1,00 & & \\
\hline RE_ratio & 0,74 & 0,12 & 0,87 & 0,74 & 1,00 & \\
\hline ChINDI & 0,75 & 0,40 & 0,94 & 0,96 & 0,74 & 1,00 \\
\hline
\end{tabular}

Table 2 Regression analysis results for the LAI estimation by using the Maccarese 2015 Rapid-Eye data set

Figure 3 shows validation of the ANN algorithm showing the relation (RMSE of 1.43 for all fields and all crops) between Green LAI (GLAI) estimated and GLAI measured (in the same fields used for the regression analysis) by using March the $8^{\text {th }}$ and April the $11^{\text {th }}$ acquisition dates. These dates correspond to the months showing a significant LAI increasing for the considered crops. Field B005 and B069 are the fields where CSK backscattered signal were compared with in situ LAI (Figure 2) and soil moisture (Figure 1).

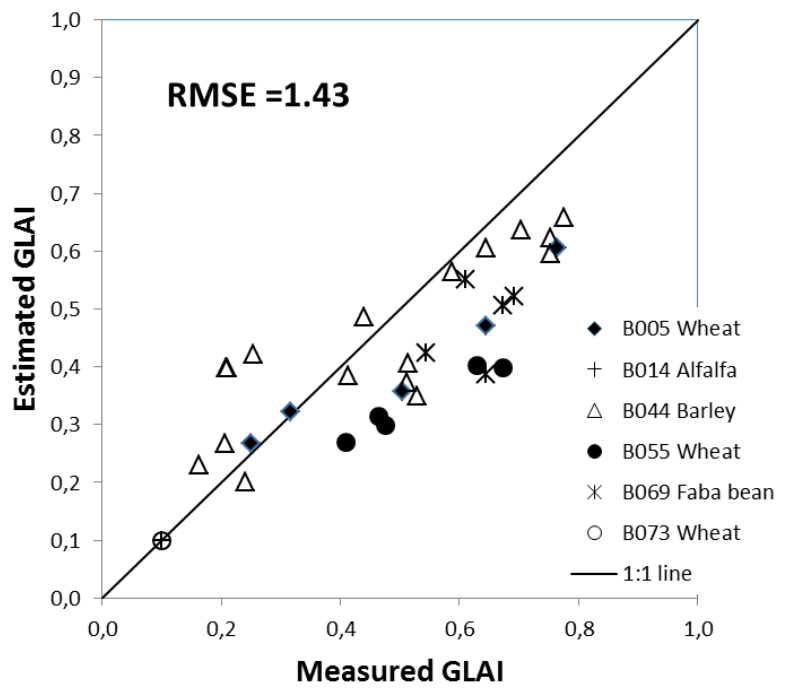

Figure 3 Graph of GLAI measured vs. GLAI estimated by the ANN procedure applied to two Maccarese Rapid-Eye images.

\section{CONCLUSION}

The paper briefly describes the preliminary results of a joint Italian-Chinese acquisition campaign in the 2015 crop growing season on the Maccarese farm (Italy) to set up a suitable optical/radar synergy to explore their potential in retrieving soil and plant information at the field scale.

The preliminary results obtained by using the multi spectral data available on Maccarese at the time of writing pertains to the winter growing phase of wheat and bean fields. At the present stage of the work radar and optical data have been processed separately. They indicate the multi-temporal behavior of CSK radar backscatter being affected in this period mainly by the soil moisture. In the early growing stage of wheat and beans, a correlation with LAI is also evident for the bean field, whereas the young wheat seems to be still quite transparent. Optical data show the potential to retrieve biophysical and biochemical characteristics for wheat and the good performance of the ANN retrieval procedures with respect the regression, even though the spectral resolution of Rapid-Eye that doesn't guarantee an accurate retrieval .

The further processing steps will include a consolidation of the retrieval procedure optimized for the Maccarese site and the exploitation of the synergistic use of radar and optical data for retrieving those bio-physical crop variables, like LAI, influencing both the reflected signal of radar and optical imagery.

\section{REFERENCES}

[1] Stankiewicz K., 2006. The efficiency of crop recognition on ENVISAT ASAR images in two growing seasons. IEEE Transcations on Geoscience and Remote Sensing, Vol. 44, No. 4, pp. 806-814.

[2] Dabrowska K., Kowalik W. and Heinzel V., "CEUBIOM Deliverable D.2.2 StuDy on Sar potential for Direct biomaSS aSSeSSment", 2009.

[3] Pierdicca, N., Chini, M., Pelliccia, F., "The Contribution of SIASGE Radar Data Integrated With Optical Images to Support Thematic Mapping at Regional Scale," Selected Topics in Applied Earth Observations and Remote Sensing, IEEE Journal of, vol. 7, no. 7, pp.2821-2833, July 2014

[4] Durden,S.L., Morrissey,L.A., and Livingston,G.P.(1995), Microwave backscatter and attenuation dependence on leaf area index for flooded rice fields", IEEE Trans.Geosci.RemoteSens.vol33,no.3,pp.807-810.

[5] Ulaby,F.T., Allen,C.T., and EgerllI,G.(1984),"Relating the microwave backscattering coefficient to leaf area index", Remote Sensing of Environment, vol.14, pp. 113-133.

[6] Rignot, E., J. Way, C. Williams, and L. Viereck, 1994. Radar estimates of above ground biomass in boreal forests of interior Alaska. IEEE Trans. Geosci. Remote Sensing, vol. 32, pp. 1117-1124.

[7] Yang H., Chena E., Li Z., Zhao C., Yang G., Pignatti S., Casa R., Zhao L. Wheat lodging monitoring using polarimetric index from RADARSAT-2 data, Int. J. of Applied Earth Observation and Geoinformation Volume 34, February 2015, Pages 157-166. doi:10.1016/j.jag.2014.08.010

[8] Baret, F., Hagolle, O., Geiger, B., Bicheron, P., Miras, B., Huc, M., \& Leroy, M. (2007). LAI, fAPAR and fCover CYCLOPES global products derived from VEGETATION. Remote Sens. of Environ. 110(3), 275-286.

[9] Casa R., Castaldi F., Pascucci S. and Pignatti S. Journal of Agricultural Science (2015), 153, 876-890. (C) Cambridge University Press 2014 doi:10.1017/S0021859614000483 